\title{
Prevalence of and risk factors
} for Plasmodium spp. co-infection with hepatitis $B$ virus: a systematic review and meta-analysis

\author{
Kwuntida Uthaisar Kotepui and Manas Kotepui (i)
}

\begin{abstract}
Background: Plasmodium spp. and hepatitis B virus (HBV) are among the most common infectious diseases in underdeveloped countries. This study aimed to determine the prevalence of Plasmodium spp. and HBV co-infection in people living in endemic areas of both diseases and to assess the risk factors related to this co-infection.

Methods: The PubMed, Web of Science, and Scopus databases were searched. Observational cross-sectional studies and retrospective studies assessing the prevalence of Plasmodium species and HBV co-infection were examined. The methodological quality of the included studies was assessed with the Newcastle-Ottawa Scale (NOS), a tool for assessing the quality of nonrandomized studies in meta-analyses, and heterogeneity among the included studies was assessed with Cochran's $Q$ test and the $I^{2}$ (inconsistency) statistic. The pooled prevalence of the co-infection and its 95\% confidence interval (CI) were estimated using the random-effects model, depending on the amount of heterogeneity there was among the included studies. The pooled odds ratio (OR) represented the difference in qualitative variables, whereas the pooled mean difference (MD) represented the difference in quantitative variables. Meta-analyses of the potential risk factors for Plasmodium spp. and HBV co-infection, including patient age and gender, were identified and represented as pooled odds ratios (OR) and $95 \%$ Cls. Publication bias among the included studies was assessed by visual inspection of a funnel plot to search for asymmetry.
\end{abstract}

Results: Twenty-two studies were included in the present systematic review and meta-analysis. Overall, the pooled prevalence estimate of Plasmodium spp. and HBV co-infection was 6\% (95\% Cl 4-7\%, Cochran's Q statistic $<0.001$,

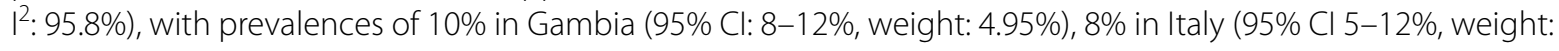
3.8\%), $7 \%$ in Nigeria (95\% Cl 4-10\%, weight: 53.5\%), and 4\% in Brazil (95\% Cl 2-5\%, weight: 19.9\%). The pooled prevalence estimate of Plasmodium spp. and HBV co-infection was higher in studies published before 2015 (7\%, 95\% Cl 4-9\%, Cochran's Q statistic < 0.001, I': 96\%) than in those published since 2015 (3\%, 95\% Cl 1-5\%, Cochran's Q statistic $\left.<0.001, I^{2}: 81.3 \%\right)$. No difference in age and risk of Plasmodium spp. and HBV co-infection group was found between the Plasmodium spp. and HBV co-infection and the Plasmodium monoinfection group (p: 0.48, OR: 1.33, 95\% $\mathrm{Cl}$ 0.60-2.96). No difference in gender and risk of Plasmodium spp. and HBV co-infection group was found between the Plasmodium spp. and HBV co-infection and HBV co-infection group and the Plasmodium monoinfection group (p: 0.09, OR: $2.79,95 \% \mathrm{Cl}$ 0.86-9.10). No differences in mean aspartate aminotransferase (AST), mean alanine aminotransferase (ALT), or mean total bilirubin levels were found ( $p>0.05$ ) between the Plasmodium spp. and HBV co-infection group and the Plasmodium monoinfection group.

*Correspondence: manas.ko@wu.ac.th

Medical Technology, School of Allied Health Sciences, Walailak University,

Tha Sala, Nakhon Si Thammarat, Thailand

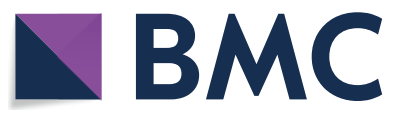

(c) The Author(s) 2020. This article is licensed under a Creative Commons Attribution 4.0 International License, which permits use, sharing, adaptation, distribution and reproduction in any medium or format, as long as you give appropriate credit to the original author(s) and the source, provide a link to the Creative Commons licence, and indicate if changes were made. The images or other third party material in this article are included in the article's Creative Commons licence, unless indicated otherwise in a credit line to the material. If material is not included in the article's Creative Commons licence and your intended use is not permitted by statutory regulation or exceeds the permitted use, you will need to obtain permission directly from the copyright holder. To view a copy of this licence, visit http://creativeco mmons.org/licenses/by/4.0/. The Creative Commons Public Domain Dedication waiver (http://creativecommons.org/publicdomain/ zero/1.0/) applies to the data made available in this article, unless otherwise stated in a credit line to the data. 
Conclusions: The present study revealed the prevalence of Plasmodium spp. and HBV co-infection, which will help in understanding co-infection and designing treatment strategies. Future studies assessing the interaction between Plasmodium spp. and HBV are recommended.

Keywords: Malaria, Plasmodium, Hepatitis B virus, HBV, Co-infection

\section{Background}

Malaria in humans is caused by the infection of at least one of the five Plasmodium species, including Plasmodium falciparum, Plasmodium vivax, Plasmodium ovale, Plasmodium malariae, and Plasmodium knowlesi [1]. Malaria is transmitted by the bite of an infected female Anopheles mosquito [2]. Malaria remains endemic among people around the world, especially people in the World Health Organization (WHO) African Region and the WHO South-East Asia Region [3]. According to the latest World Malaria Report 2019, there were an estimated 228 million cases of malaria with an estimated number of malaria deaths at 405,000, mostly children under 5 years of age (67\%) [4]. Most malaria cases were reported from six countries in the African region including Nigeria (25\%), the Democratic Republic of the Congo (12\%), Uganda (5\%), Côte d'Ivoire (4\%), Mozambique (4\%) and Niger (4\%) [4]. Hepatitis B infection is caused by hepatitis $B$ virus (HBV), a double-stranded DNA virus belonging to the Hepadenaviridae family, and its infection leads to a wide range of clinical spectra from acute to chronic hepatitis, cirrhosis, and hepatocellular carcinoma [5]. The infection of HBV in individuals was acquired through exposure to potentially infectious blood or blood products or through percutaneous exposure to sharp contamination [6]. Globally, an estimated 257 million people were living with chronic HBV infection in 2015, and most people in the WHO African Region and the Western Pacific Region were affected [7]. The reduction in HBV prevalence among children (1.3\%) was seen after the introduction of the hepatitis B vaccine in 2015 [7].

Plasmodium spp. and HBV infections are endemic among people residing in the same regions and are prone to co-infect individuals because of their geographical coincidence $[8,9]$. In individuals with Plasmodium spp. and HBV co-infection, the two pathogens use the liver as their host during their developmental stages, which may result in liver injuries and lead to increased mortality and morbidity [10]. A previous study demonstrated that HBV infections could reduce the ability of the liver to kill Plasmodium parasites $[10,11]$. A study in patients with Plasmodium spp. and HBV co-infection demonstrated that $P$. falciparum modulates $\mathrm{HBV}$ viremia in patients with chronic HBV infection [12]. A study conducted in Asia proposed that chronic HBV infection may lead to the synergistic multiplication of $P$. falciparum malaria, but the overall risk of death was not significantly higher in coinfected patients [13]. Another study proposed that HBV infection might reduce the density of Plasmodium parasites in malaria patients with no organ dysfunction [9], while a previous study demonstrated that Plasmodium and HBV co-infection significantly increased the density of malaria parasites [14].

Currently, studies on the risk factors for Plasmodium spp. and HBV co-infection and the differences in liver function tests (LFTs) are sparse and inconsistent. Demographic profiles of patients, including age and gender, might explain the possible risks for co-infection, as suggested by previous studies indicating that most cases of Plasmodium spp. and HBV co-infection occured in patients aged $20-50$ years $[15,16]$, while another study demonstrated a higher proportion of Plasmodium spp. and HBV co-infection cases among patients who are $\geq 50$ years of age [17]. A better understanding of the overall prevalence of Plasmodium spp. and HBV co-infection, the potential risk factors, and the LFTs in infected individuals could help endemic countries to diagnose, prevent, and control Plasmodium spp. and HBV co-infection. Therefore, the present study aimed to synthesize evidence regarding Plasmodium spp. and HBV co-infection using a meta-analytic approach and to assess the effects of demographic profiles, including age and gender, on the risks of Plasmodium spp. and HBV coinfection. In addition, the differences in the levels of LFTs between individuals with Plasmodium spp. and HBV coinfection and those with Plasmodium spp. monoinfection were also investigated.

\section{Methods}

\section{Protocol and registration}

This study was conducted in accordance with the Preferred Reporting Items for Systematic Reviews and Meta-analyses (PRISMA) guidelines, which provide an evidence-based minimum set of items for reporting in systematic reviews and meta-analyses (PRISMA Checklist S1) [18]. The protocol was registered at the International Prospective Register of Systematic Reviews (PROSPERO) with a registration number: CRD42020196790. Plasmodium spp. infections were diagnosed by a standard method, microscopy or other alternative methods, including polymerase chain reaction (PCR), rapid diagnosis test (RDT), or a combination of 
those methods. HBV infections were diagnosed by RDT or PCR, enzyme-linked immunosorbent assay (ELISA), or a combination of those methods.

\section{Search strategies}

The PubMed, Web of Science, and Scopus databases were searched for studies on co-infection with Plasmodium spp. and HBV that were published prior to April 16, 2020. To maximize the search, only three Medical Subject Headings (MeSH) were used: (malaria OR plasmodium) AND "hepatitis B" AND "co-infection". To maximize the number of included studies, studies on humans published in any language were considered. The references of the included studies and relevant review articles were also reviewed to identify additional relevant studies.

\section{Eligibility criteria and selection of studies}

Studies were included in this study if they were (1) observational studies performed on participants coinfected with Plasmodium spp. and HBV and (2) observational studies reporting on the number of Plasmodium spp. and HBV coinfected and monoinfected participants. Studies that did not meet the inclusion criteria were excluded, including animal studies, books and book chapters, experimental studies, studies on malaria co-infection with other pathogens, studies that did not examine coinfection, case reports/case series, randomized control trials, studies with a similar group of participants, and studies with no full text available. The relevant review articles were stored and reviewed as potentially eligible articles that met the inclusion criteria only, but they were not included in the meta-analysis.

\section{Data extraction}

Two authors (MK and KUK) independently screened and selected the relevant studies related to the eligibility criteria. Data from the potentially eligible studies were retrieved and extracted to a standardized data extraction form (Microsoft Excel, Microsoft Corporation, USA). Any discrepancies in study selection and extractions were resolved by consensus or discussion. Information on authors, year of publication, study area, years of the study conducted, study design, age range, gender, number of Plasmodium spp. monoinfections, number of HBV monoinfections, number of Plasmodium spp. and HBV co-infection, detection methods for Plasmodium spp. and HBV, and laboratory data (LFTs) were extracted.

\section{Quality of the included studies}

The quality of the included studies was determined following the Newcastle-Ottawa Scale (NOS), a tool for assessing the quality of nonrandomized studies in meta-analyses that consists of three domains: selection, comparability, and outcomes [19]. A maximum of six stars (the highest quality) for the cross-sectional and retrospective studies was modified from the NOS to assessing the quality of the included studies. Any studies rated $\geq 5$ stars were considered high-quality studies, while studies rated $<5$ stars were considered low-quality studies (Table 2).

\section{Data synthesis}

The primary outcome of the present study was the pooled prevalence of Plasmodium spp. and HBV co-infection, which was estimated using the Freeman-Tukey double arcsine transformation method with the DerSimonian and Laird random-effects model. These analyses were run using the "metaprop" command provided in Stata (StataCorp, USA) [20, 21]. In 2015, the WHO released the 'WHO Guidelines for the treatment of malaria' [22], which consisted of recommendations on the diagnosis and treatment of severe and uncomplicated malaria among at-risk populations [22]. The subgroup analysis of the pooled prevalence estimate between years of studies conducted (year 2014 or less, year 2015 and beyond) was performed to identify any differences in the pooled prevalence estimate between subgroups. The secondary outcome of the present study was the pooled effect estimates (odds ratio, OR) for the age group, gender, aspartate aminotransferase (AST) levels, alanine aminotransferase (ALT) levels, and total bilirubin levels. Differences in the effect estimates between the groups were examined. The results of the pooled effect estimates were presented as a pooled OR and its $95 \%$ confidence interval (CI) for dichotomous variables, whereas the results of the pooled effect estimates were presented as pooled mean difference (MD) and its 95\% CI for continuous variables. The heterogeneity across the included studies was assessed with Cochran's $Q$ test and Higgins $\mathrm{I}^{2}$ (inconsistency) statistic. A significant Cochran's $Q$ test $(\mathrm{p}<0.05)$ with an $\mathrm{I}^{2}$ value greater than $50 \%$ indicated substantial heterogeneity. The fixed-effects model was used in cases of no significant heterogeneity, while the random-effects model was used in cases of significant heterogeneity across the included studies.

\section{Publication bias assessment}

The publication bias among the included studies was assessed by a visual inspection of the funnel plot to search for asymmetry (the asymmetrical distribution of the included studies in the graph between the OR and SE $(\log \mathrm{OR}))$. The funnel plot was generated with data 
on the age of participants and status of Plasmodium spp. and HBV co-infection.

\section{Results}

\section{Characteristics of the included studies}

The process of the present systematic review is demonstrated in the study flow diagram (Fig. 1). The initial search yielded 1,075 articles, and the titles and abstracts of 965 articles were screened. The full texts of 102 articles that met the inclusion criteria were screened. Finally, 9 studies [8-10,23-28] were included in the quantitative synthesis. Thirteen additional studies [11, 14-17, 29-36] were identified and included after reviewing the references of the nine included studies and additional searches of other databases. The main characteristics of the 22 included studies $[8-11,14-17,23-36]$ are presented in Table 1 . Of the 22 included studies, 13 studies [9-11, 14, 16, 17, 24, 26, $28,31,32,34,35]$ were conducted before 2015, while three studies $[23,29,30]$ were conducted in or after

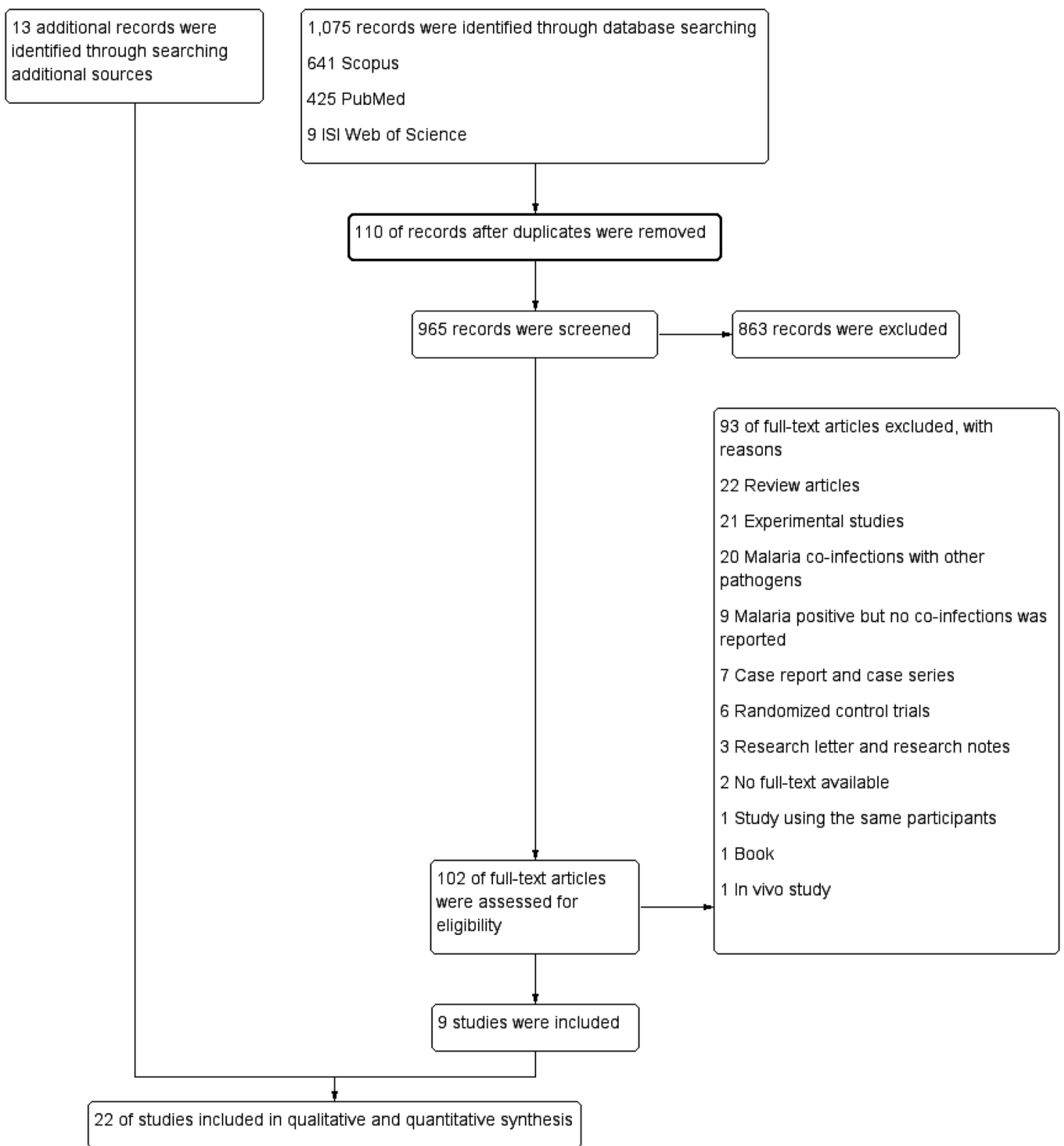

Fig. 1 Flow chart for the study selection 


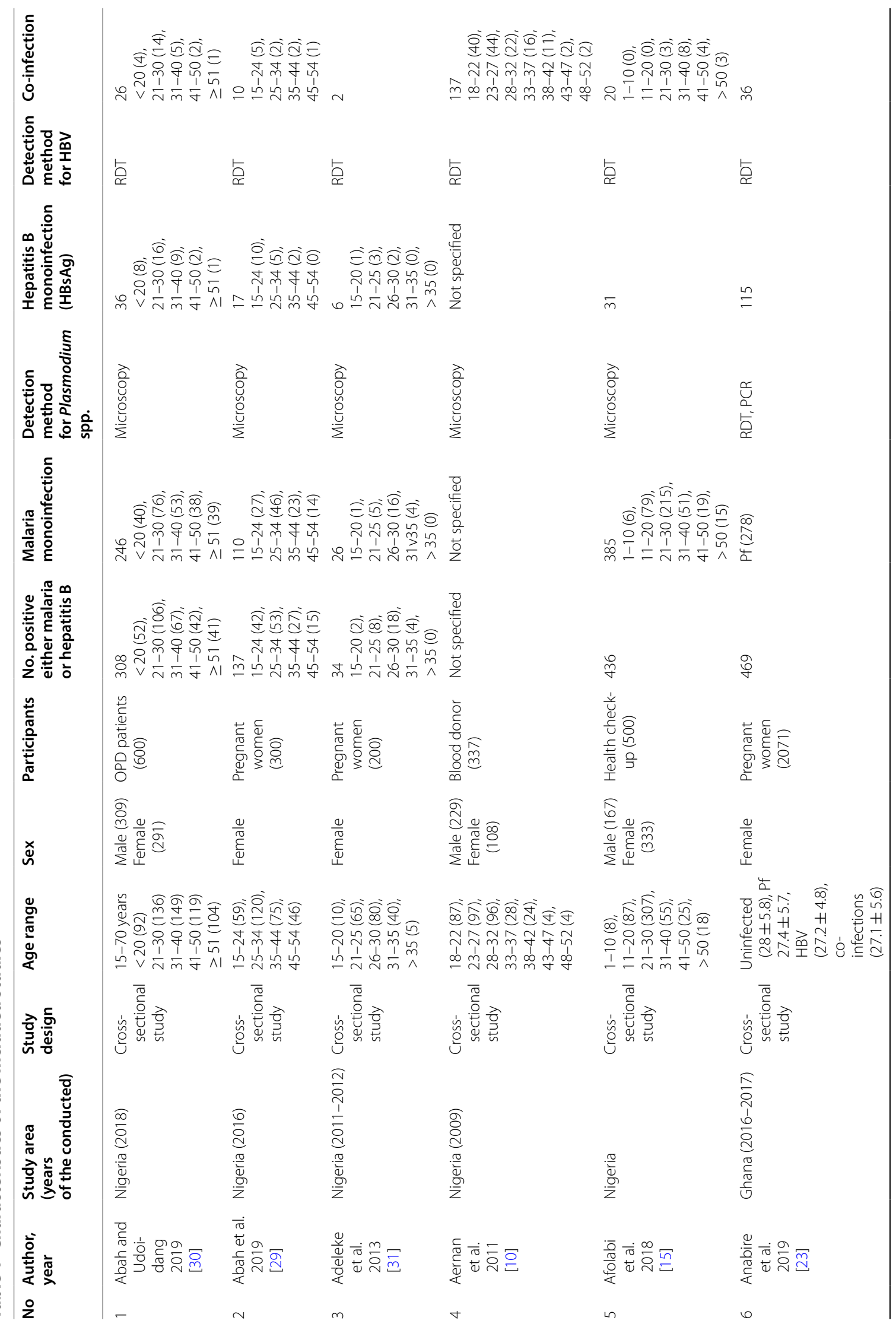




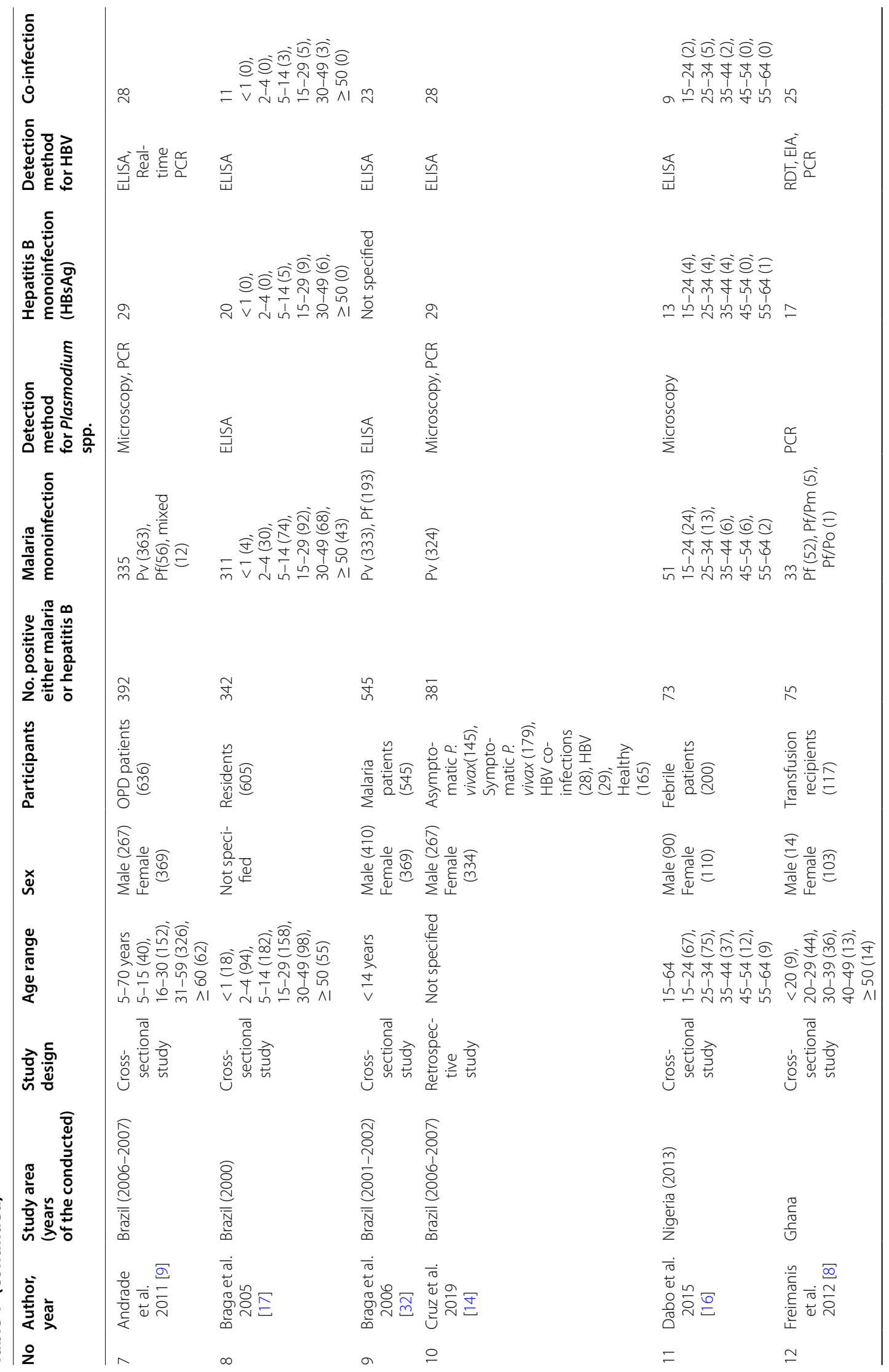




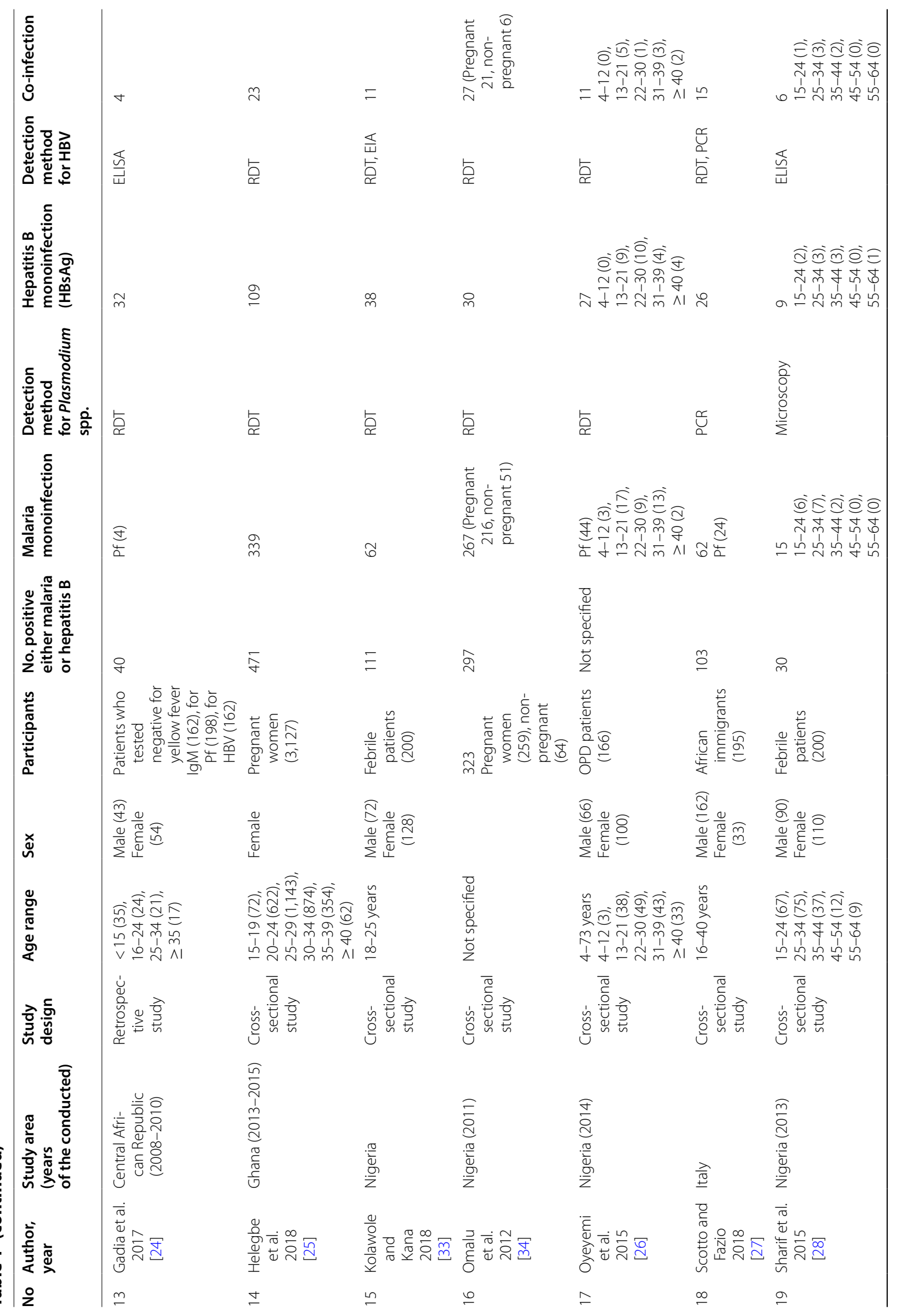




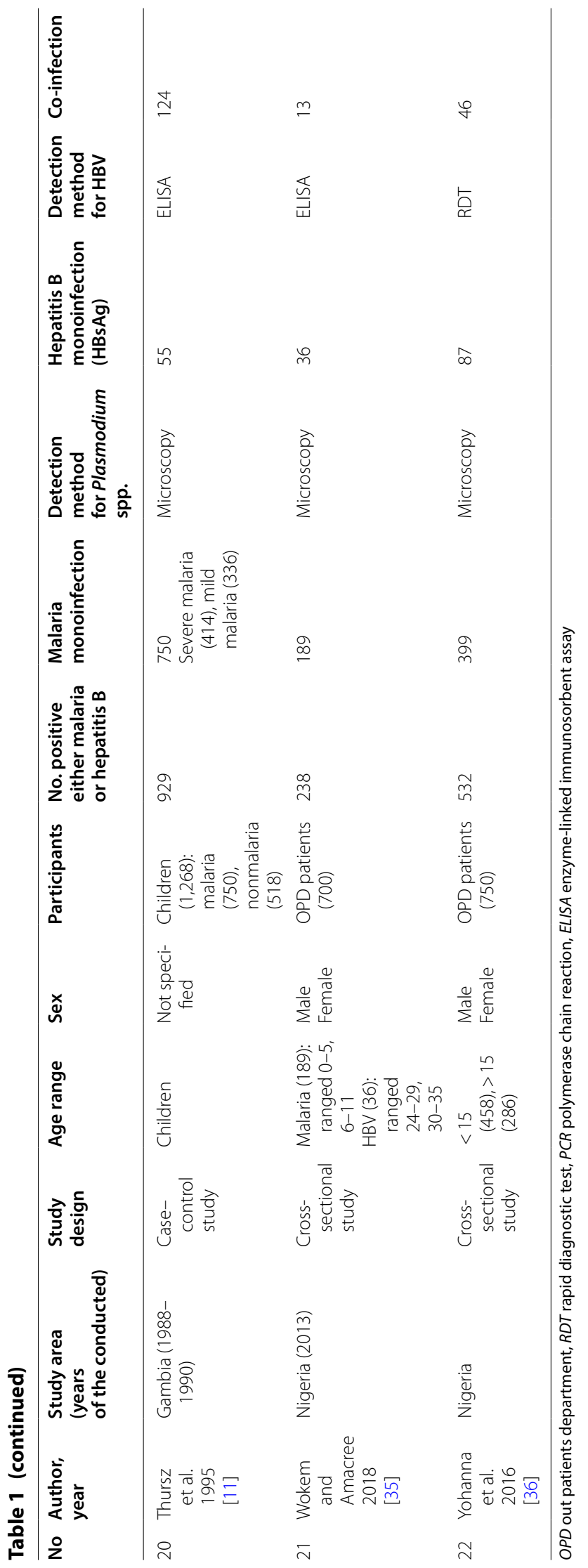


2015. One study was conducted during 2013-2015, while five studies $[8,15,27,33,36]$ did not specify the year of study conducted. Among the 22 included studies, approximately half of the studies $(12 / 22 ; 54.5 \%)$ were carried out in Nigeria [10, 15, 16, 26, 28-31, 3336 , while the remaining 10 studies were carried out in Brazil [9, 14, 17, 32], Ghana [8, 23, 25], Central African Republic [24], Italy [27], and The Gambia [11]. Twenty of the 22 included studies used cross-sectional designs, while two studies used retrospective designs. The age range of participants was reported in 20 studies, whereas 2 studies did not report the age range of their participants. Approximately half of the included studies $[8-10,14-16,24,26-28,30,32,33,35,36](15 / 22$; $68.2 \%)$ performed studies on both men and women, while four studies [23, 25, 29, 31] performed studies only in females. The sex of the participants was not specified in two studies [11, 17]. Five studies [9, 26, 30, $35,36]$ examined patients seeking care at hospitals, five studies examined pregnant women [23, 25, 29, 31, 34], three studies $[16,28,33]$ examined febrile patients, one study examined blood donors [10], one study examined residents [17], one study examined malaria patients [32], one study examined patients attending health check-ups [15], one study examined transfusion recipients [8], one study examined patients who tested negative for yellow fever [24], one study examined African immigrants [27], one study examined children [11], and one study enrolled patients with asymptomatic/symptomatic $P$. vivax, patients with HBV infection/co-infection, and healthy individuals [14]. Ten studies [10, 11, $15,16,28-31,35,36]$ used only standard microscopy, five studies [24-26, 33, 34] used only RDT, two studies $[8,27]$ used only PCR, two studies $[8,27]$ used both microscopy and PCR, one study [23] used both RDT and PCR, and one study [17] used ELISA for the detection of malaria parasites. The detection methods for Plasmodium spp. and HBV and the number of patients with Plasmodium spp. monoinfection and Plasmodium spp. and HBV co-infection are shown in Table 1.

\section{The prevalence of Plasmodium spp. and HBV co-infection}

All 22 studies included in the present systematic review and meta-analysis provided data on the prevalence of Plasmodium spp. and HBV co-infection. The results showed that the prevalence estimate of Plasmodium spp. and HBV co-infection among 22 studies varied widely, ranging between 1 and $41 \%$. The highest proportion of Plasmodium spp. and HBV co-infection was found in Nigerian blood donors (41\%) as reported by Aernan et al. [10]. Overall, the pooled prevalence estimate of Plasmodium spp. and HBV co-infection was 6\% (95\% CI
4-7\%, Cochran's $Q$ statistic $\left.<0.001, \mathrm{I}^{2}: 95.8 \%\right)$, and there was highly significant heterogeneity $\left(\mathrm{p}<0.001, \mathrm{I}^{2}: 95.8 \%\right)$ among the included studies (Fig. 2).

\section{Subgroup analysis on the prevalence of Plasmodium spp. and HBV co-infection}

A subgroup analysis of the pooled prevalence estimate between studies conducted before 2015 and studies conducted since 2015 revealed that the pooled prevalence estimate of Plasmodium spp. and HBV co-infection in 13 studies published before 2015 was 7\% (95\% CI 4-9\%, Cochran's $Q$ statistic $<0.001, \mathrm{I}^{2}: 96 \%$ ), while the pooled prevalence estimate of Plasmodium spp. and HBV coinfection in three studies published since 2015 was 3\% (95\% CI $1-5 \%$, Cochran's $Q$ statistic $<0.001, \mathrm{I}^{2}: 81 \%$ ). The pooled prevalence estimate of Plasmodium spp. and HBV co-infection in studies conducted during 2013-2015 and studies that did not specify the year of studies conducted are demonstrated in Fig. 2.

Subgroup analysis of the pooled prevalence of Plasmodium spp. and HBV co-infection between studies conducted in different countries was also analysed. The results showed that the pooled prevalence estimate of Plasmodium spp. and HBV co-infection was $8 \%$ in Italy (95\% CI $5-12 \%), 7 \%$ in Nigeria (95\% CI $4-10 \%, \mathrm{I}^{2}$ : 95.41\%), $4 \%$ in Brazil (95\% CI 2-5\%, $\left.\mathrm{I}^{2}: 79.02 \%\right), 2 \%$ in Ghana (95\% CI 1-1\%, I'2: 94.32\%), 2\% in the Central African Republic (95\% CI 1-6\%), and 1\% in Gambia (95\% CI 8-12\%) (Fig. 3).

\section{Differences in age, gender and potential risk of Plasmodium spp. and HBV co-infection}

The identified studies were classified into subgroups by age and gender (Additional file 1: Table S1). Among the seven included studies, there was no difference in the age of individuals between the Plasmodium spp. and HBV co-infection group and the Plasmodium spp. monoinfection group (p: 0.18, OR: 1.33 , 95\% CI $0.6-$ 0.96 , Cochran's $Q$ statistic $\left.<0.0001, \mathrm{I}^{2}: 69 \%\right)$. Subgroup analysis of age groups $(<20,20-50$, and $\geq 50$ years $)$ was performed to identify any difference in age and risk of Plasmodium spp. and HBV co-infection. The results showed that no significant difference in age and risk of Plasmodium spp. and HBV co-infection was found in participants aged $20-50$ years (p: 0.12, OR: $2.97,95 \%$ CI 0.76-11.56), <20 years (p: 0.33, R: 0.67, 95\% CI 0.301.49 ), and $\geq 50$ years (p: 0.85 , OR: $0.84,95 \%$ CI $0.15-4.77$ ) (Fig. 4).

An analysis of gender and risk of Plasmodium spp. and HBV co-infection was performed. The results showed that among the five included studies, there was no significant difference in gender and risk of Plasmodium spp. 


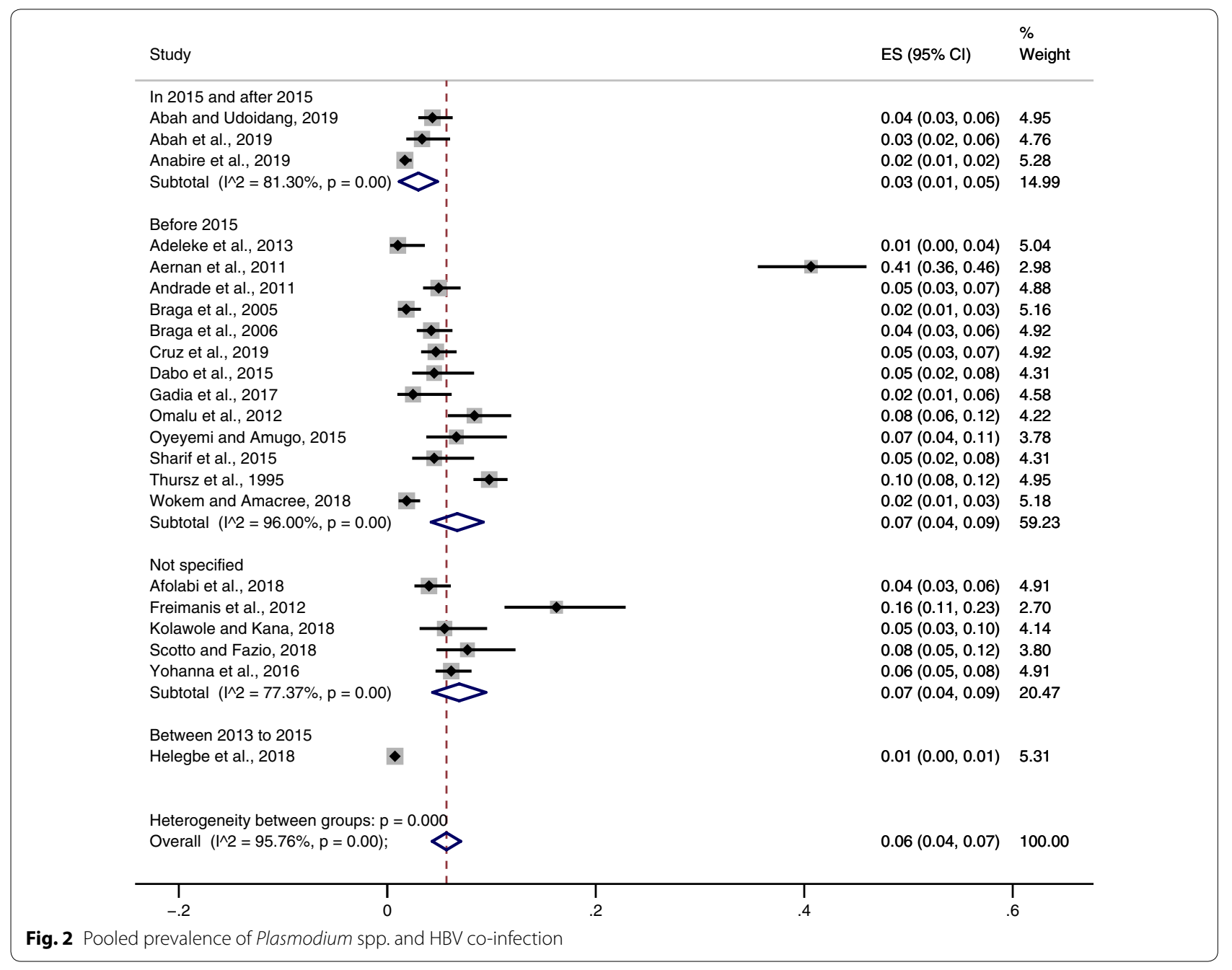

and HBV co-infection (p: 0.09, OR: 2.79 , 95\% CI 0.869.10, $\mathrm{I}^{2}:$ 84\%) (Fig. 5). The highest proportion of males (OR: 16.1, 95\% CI 7.5-34.7) was found in blood donors as reported by Aernan et al. [10].

\section{Differences in LFTs between Plasmodium spp. and HBV co-infection and Plasmodium spp. monoinfection}

Only two studies $[14,28]$ reported the AST, ALT, and total bilirubin levels and were included in the metaanalysis of mean differences (Additional file 2: Table S2). The results showed that no significant difference in AST levels was found between the Plasmodium spp. and HBV co-infection group and the Plasmodium spp. monoinfection group (p: 0.32, MD: -47.8, 95\% CI -142.2-46.6, Cochran's $Q$ statistic $\left.<0.00001, \mathrm{I}^{2}: 100 \%\right)$. No significant difference in ALT levels was found between the Plasmodium spp. and HBV co-infection group and the Plasmodium spp. monoinfection group (p: 0.32, OR: -50.5 , 95\% CI -150.2-49.3, Cochran's $Q$ statistic $<0.00001, \mathrm{I}^{2}$ :
100\%). No significant difference in total bilirubin levels was found between the Plasmodium spp. and HBV coinfection group and the Plasmodium spp. monoinfection group (p: 0.47, MD: -0.59, 95\% CI -2.17-1.0, Cochran's $Q$ statistic $<0.00001, \mathrm{I}^{2}: 99 \%$ ) (Fig. 6).

\section{Quality of the included studies}

Overall, the quality of the 22 included studies was assessed using the NOS with some modifications for cross-sectional and retrospective studies. All included studies were high-quality and had ratings ranging from six stars to seven stars (Table 2).

\section{Publication bias}

The funnel plot revealed an asymmetrical distribution of the included studies in the graph between the OR and SE (logOR) (Fig. 7), indicating publication bias due to the small study effects. 


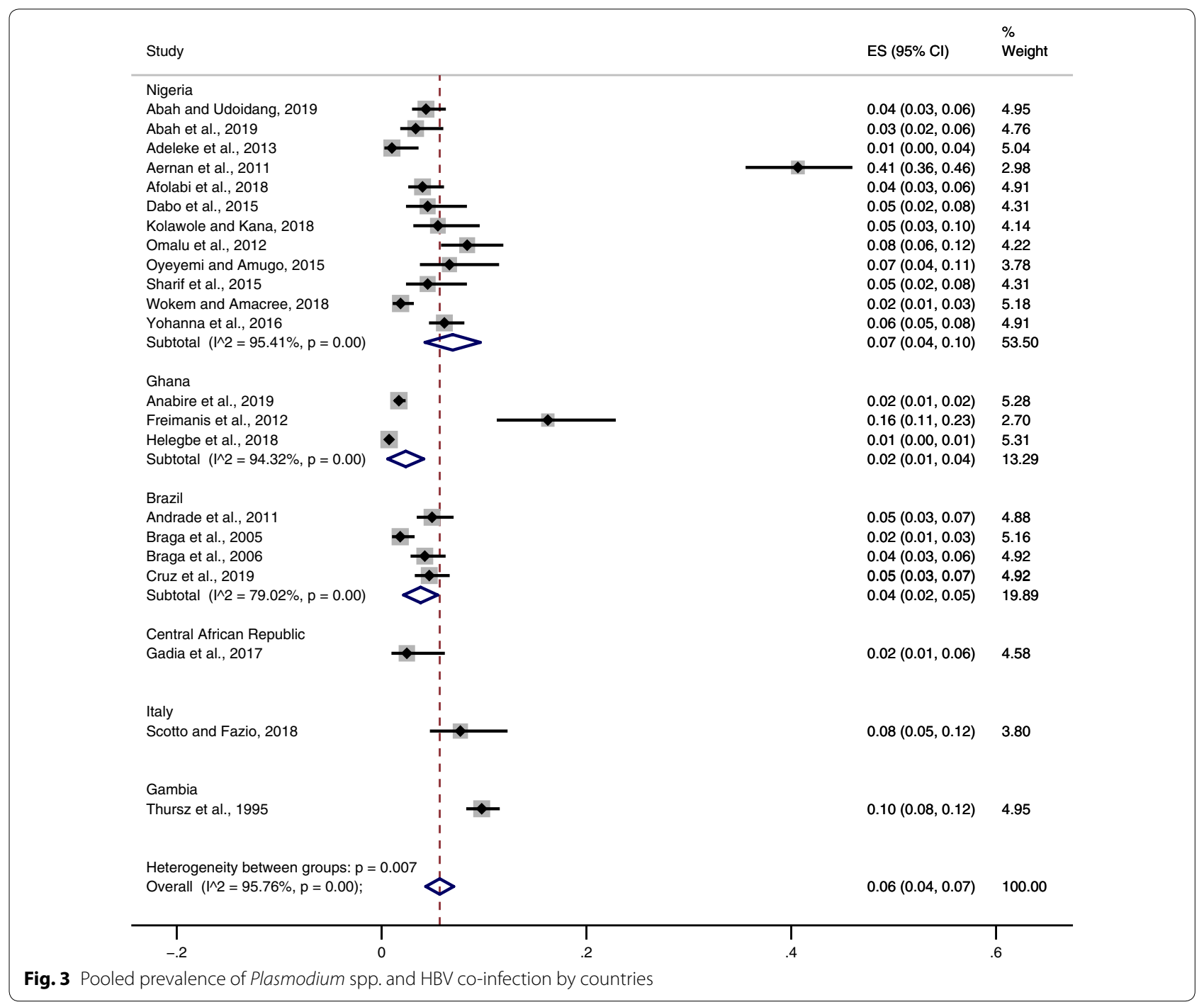

\section{Discussion}

The present systematic review and meta-analysis provided information on the overall prevalence of Plasmodium spp. and HBV co-infection. The results demonstrated that there was a high prevalence estimate of Plasmodium spp. and HBV co-infection (6\%). Nevertheless, the pooled prevalence estimate of Plasmodium spp. and HBV co-infection was not precisely estimated, as indicated by the highly significant amount of heterogeneity among the included studies $\left(\mathrm{I}^{2}=95.76, \mathrm{p}<0.001\right)$. When assessing the individual studies, Plasmodium spp. and HBV co-infection was prevalent in most tropical and sub-Saharan African countries, particularly Nigeria $[10,15,16,26,28-31,33-36]$, Ghana [8, 23, 25], Central African Republic [24], and The Gambia [11]. The pooled prevalence estimate of Plasmodium spp. and HBV coinfection was highest (6\%) among the included studies conducted in Nigeria. However, due to the significant amount of heterogeneity $\left(\mathrm{p}<0.001, \mathrm{I}^{2}: 95.41 \%\right)$ across these included studies, the pooled prevalence estimate in Nigeria might be confounded by at least one study conducted in Nigerian blood donors, which reported the highest proportion of Plasmodium spp. and HBV coinfection (41\%) [10]. Compared with studies conducted in Nigeria, the pooled prevalence estimate of Plasmodium spp. and HBV co-infection in Ghana was lower in the included studies (2\%). There was also a significant amount of heterogeneity in the pooled subgroup analysis ( $\left.\mathrm{p}<0.001, \mathrm{I}^{2}: 94.32 \%\right)$, which might be due to at least one study reporting a prevalence of $16 \%$ among transfusion recipients [8]. The pooled prevalence estimate of Plasmodium spp. and HBV co-infection in studies conducted in Brazil showed the lowest amount of heterogeneity $\left(\mathrm{p}<0.001, \mathrm{I}^{2}: 79.02 \%\right)$ compared with studies conducted in Nigeria and Ghana. The study conducted 


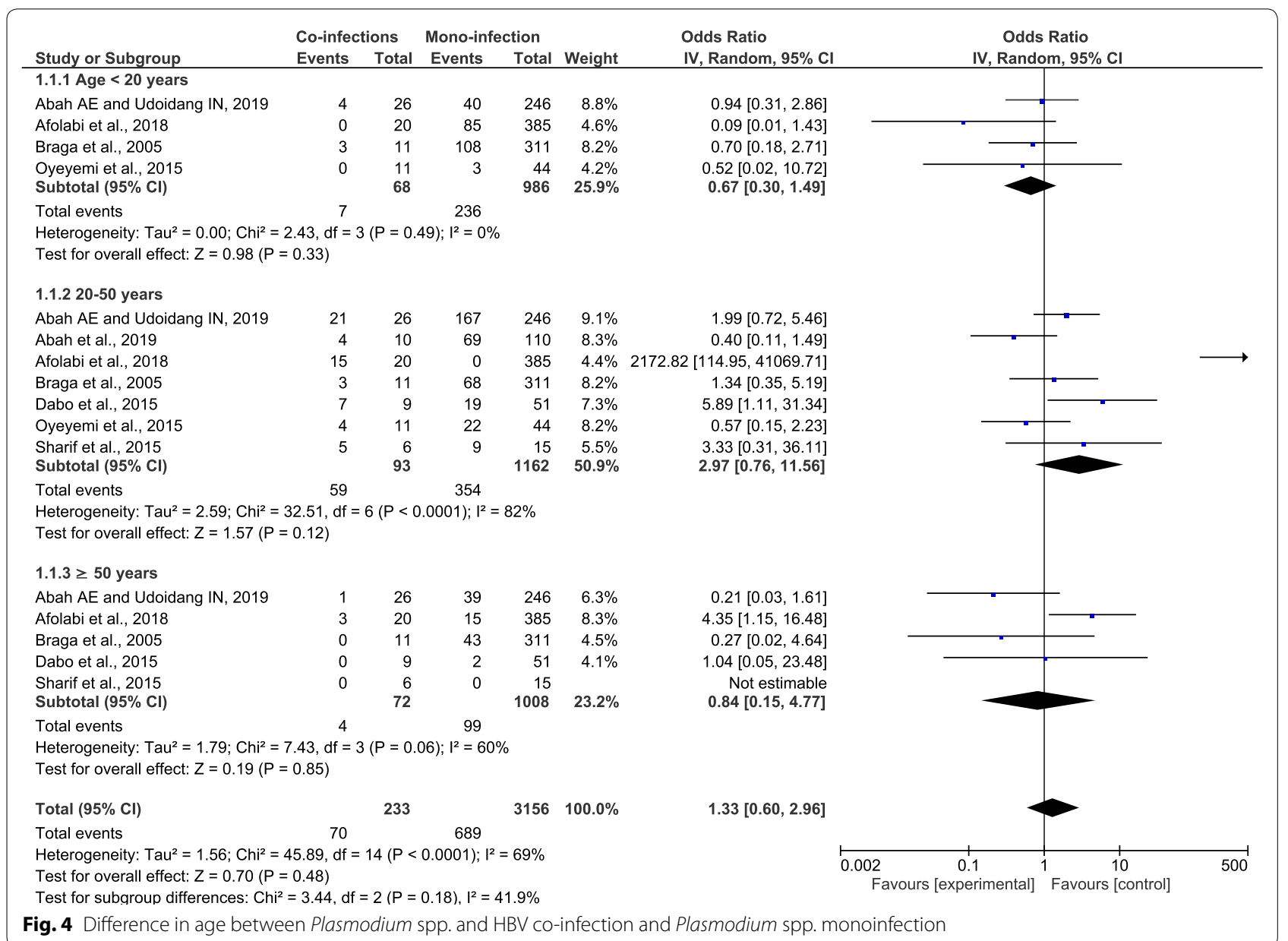

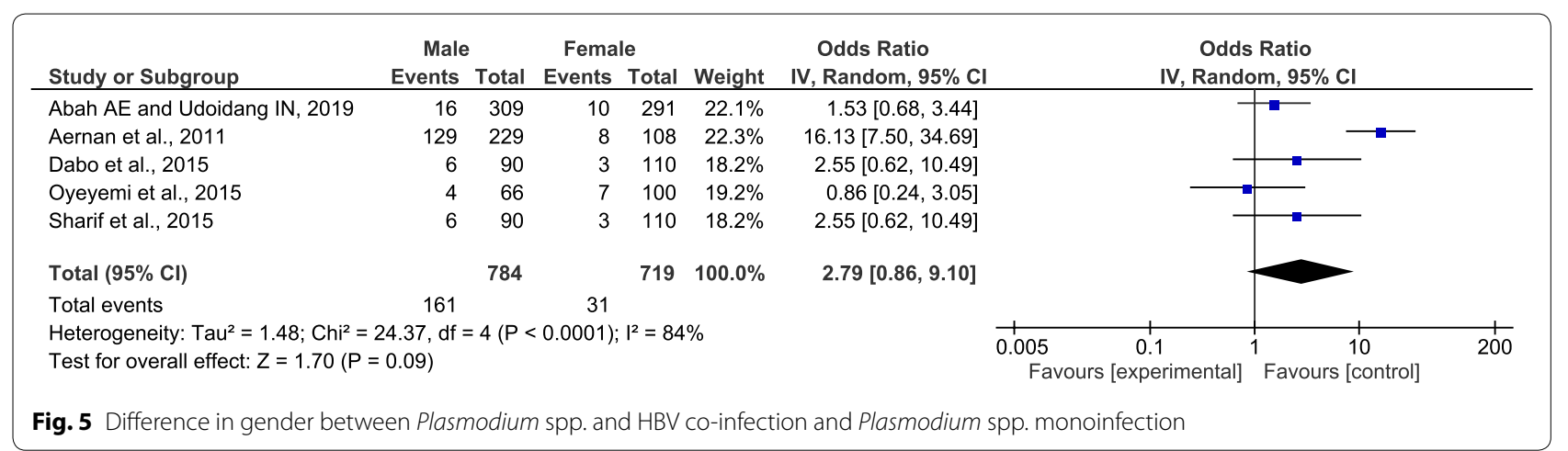

among African immigrants in Italy reported a high prevalence of Plasmodium spp. and HBV co-infection and suggested that this finding was due to the participants having acquired semi-immunity with submicroscopic levels of parasitaemia, resulting in no sign or symptoms of malaria before detection [27].

The subgroup analysis of the years of studies revealed that the pooled prevalence estimate of Plasmodium spp. and HBV co-infection was higher among studies conducted before 2015 (7\%) than those conducted since 2015 (3\%). However, the pooled prevalence of Plasmodium spp. and HBV co-infection among studies conducted before 2015 was not precisely estimated, as indicated by the significant amount of heterogeneity among the 13 included studies [9-11, 14, 16, 17, 24, 26, $28,31,32,34,35]\left(\mathrm{p}<0.001, \mathrm{I}^{2}: 96 \%\right)$. The pooled prevalence of Plasmodium spp. and HBV co-infection among studies conducted since 2015 (3\%) was lower than the 


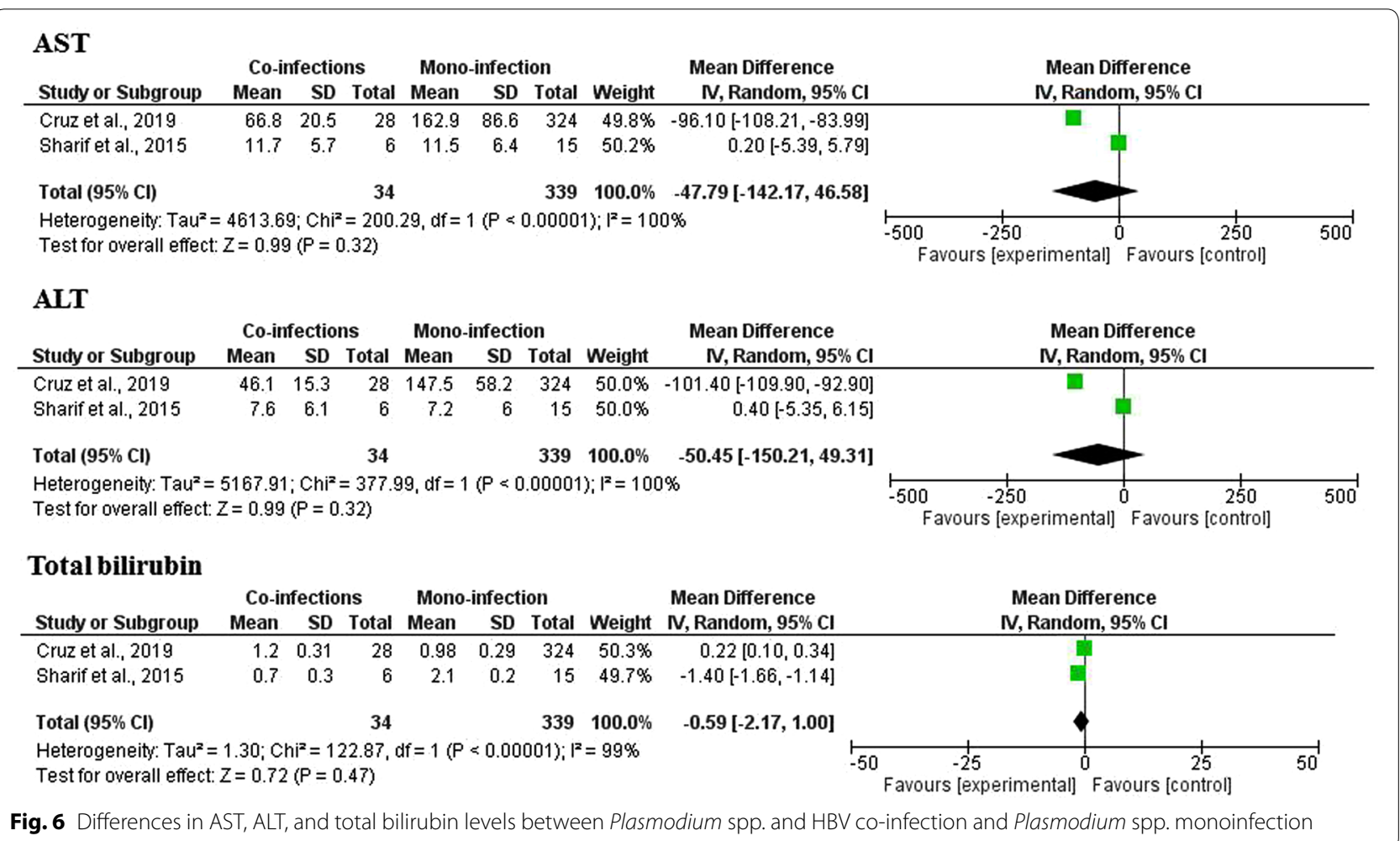

prevalence among studied conducted before 2015. In addition, a significantly lower amount of heterogeneity among the three studies $[23,29,30]\left(\mathrm{p}<0.001, \mathrm{I}^{2}: 81.3 \%\right)$ was found, indicating a more reliable pooled prevalence estimate of Plasmodium spp. and HBV co-infection than the prevalence among the studies conducted before 2015 . In light of these results, the reduction in the pooled prevalence between studies conducted in and after 2015 compared with studies conducted before 2015 might be due to the new WHO guidelines implemented in 2015, which updated the recommendations for the treatment of malaria, including the dosing of drugs in children and the use of drugs for preventing malaria in high-risk groups (young children, pregnant women, tuberculosis or HIV/ AIDS patients, non-immune travellers) [22].

Little is known about the effect of Plasmodium spp. and HBV co-infection on disease severity. The interaction between two pathogens in hosts has been studied. The interactions between Plasmodium spp. and HBV in the same individuals in Papua New Guinea demonstrated that patients with severe malaria had the lowest prevalence of HBV infection [37]. The study of the immune response among patients with malaria and HBV coinfection demonstrated a robust pro-inflammatory Type 1 immune response (Th1), which is important for Plasmodium spp. clearance induced by HBV; nevertheless, it caused disease severity from co-infection [38]. HBV replication in liver cells also enhanced the production of interferon (IFN) $-\gamma$ and IFN- $\alpha / \beta$. A study in experimental mice demonstrated that intrahepatic HBV replication was inhibited by the Plasmodium yoelii 17X NL [39]. They also reported that Plasmodium spp. and HBV coinfected individuals demonstrated elevated concentrations of IL-10 (eight-fold) and C-C Motif Chemokine Ligand 2 (CCL2) in comparison to those with $P$. vivax infection [14]. CCL2 has been reported to be produced by hepatocytes during HBV infection [40] and is related to P. vivax infection [41].

A meta-analysis was conducted to determine whether age was a potential risk factor for Plasmodium spp. and HBV co-infection. The meta-analysis of age included seven studies $[15-17,26,28-30]$ and revealed that no significant difference in age was found between the Plasmodium spp. and HBV co-infection group and the Plasmodium spp. monoinfection group. There was a significant heterogeneity among the included studies $\left(\mathrm{p}<0.0001, \mathrm{I}^{2}: 69 \%\right)$. To explore the source of heterogeneity among the included studies that might affect the pooled OR estimate, a subgroup analysis of age $(<20$, $20-50$, and $>50$ years of age) was performed. The subgroup analysis demonstrated that no significant difference in age or risk of co-infection was found among the three age groups. The pooled OR estimates were reliable in individuals aged $<20\left(\mathrm{p}<0.49, \mathrm{I}^{2}: 0 \%\right)$ and those 


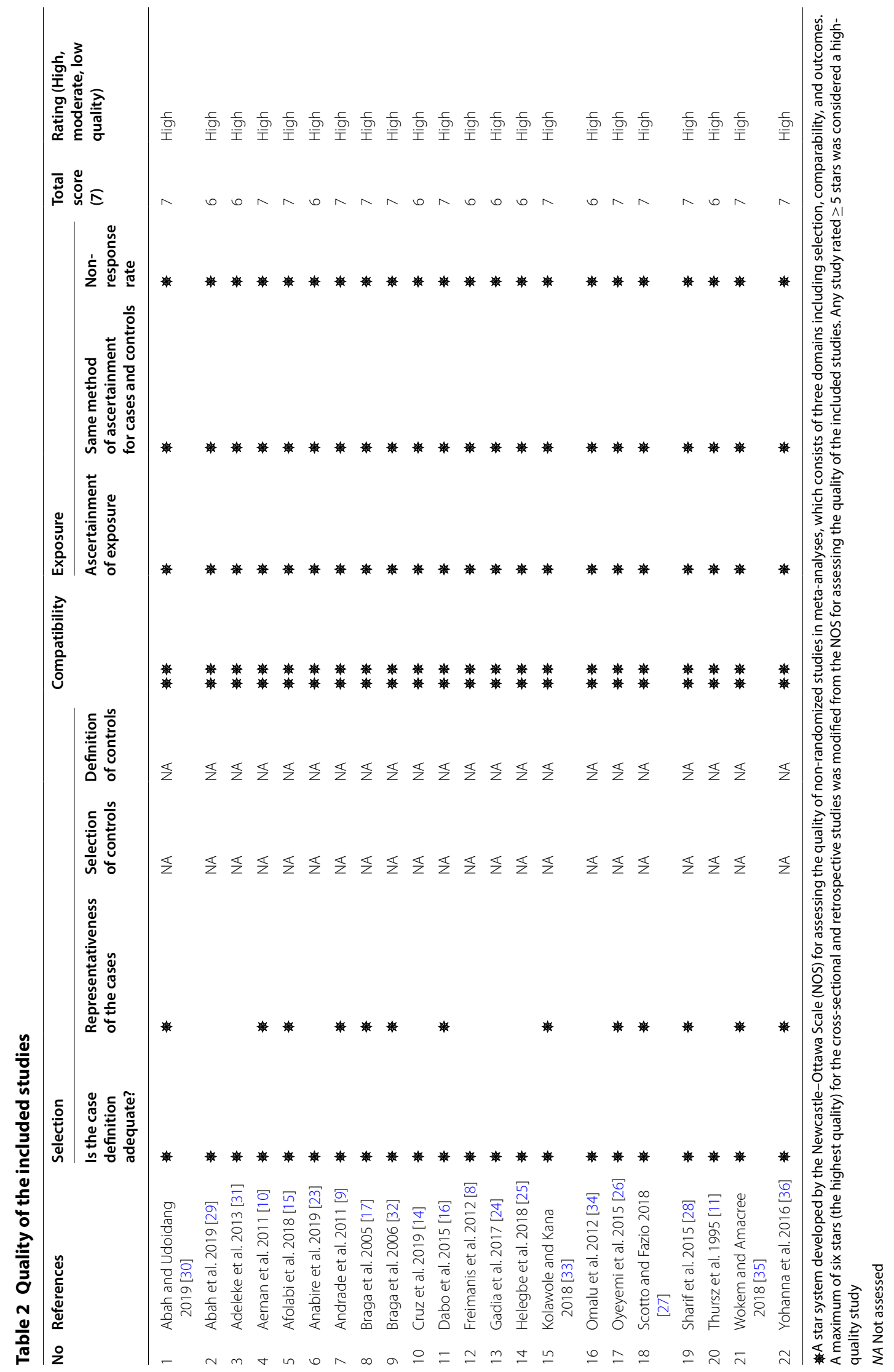




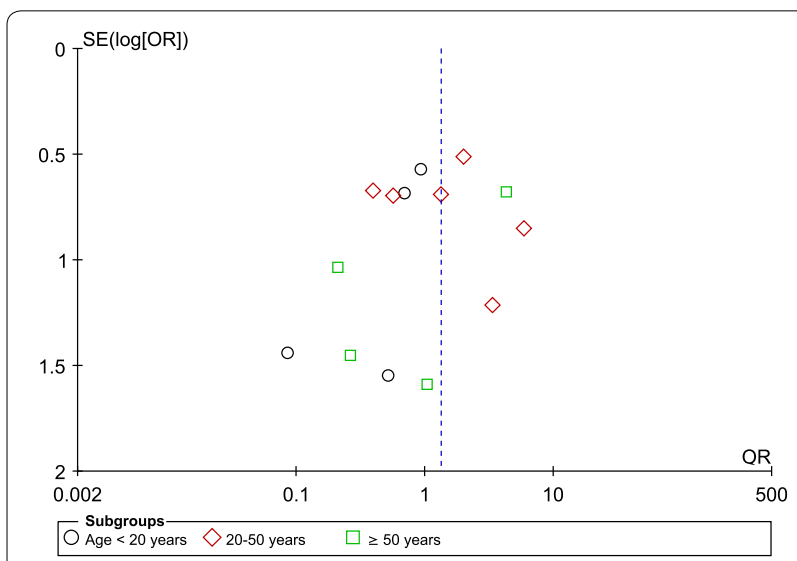

Fig. 7 Funnel plot

aged $>50$ years (p: $0.06, \mathrm{I}^{2}: 60 \%$ ) with no significant amount of heterogeneity among the included studies. This finding implies that an age $<20$ and an age $>50$ years were not potential risk factors for Plasmodium spp. and HBV co-infection, while the pooled OR estimates of age were not reliable in individuals aged between $20-50$ years, as indicated by the significant amount of heterogeneity among the included studies $\left(\mathrm{p}<0.0001, \mathrm{I}^{2}\right.$ : $82 \%$ ). This means that an age between 20 and 50 years old might be a potential risk factor for Plasmodium spp. and HBV co-infection, but this finding could not be confirmed in the present meta-analysis and needs to be evaluated by further longitudinal studies. In light of these results, research conducted in individuals aged between $20-50$ years by two studies, Afolabi et al. [15] and Dabo et al. [16], demonstrated the highest prevalences of Plasmodium spp. and HBV co-infection in their studies. The higher prevalence of Plasmodium spp. and HBV co-infection among the youthful age group could be attributed to their higher-risk behaviours for infection by both Plasmodium spp. and HBV, including unprotected sexual activities, drug abuse, fashionable tattooing and skin piercing, the lack of mosquito nets for beds, and failure to complete the recommended drug doses for treatments $[10,30]$. Another possible explanation for the high proportion of Plasmodium spp. and HBV co-infection among the youthful age group could be explained by females in this age group giving birth to children. These females (pregnant) visited clinics or hospitals during their pregnancy health check-up, which resulted in a diagnosis and contributed to the high prevalence of Plasmodium spp. and HBV co-infection. This rationale was supported by the high proportion of pregnant women coinfected with Plasmodium spp. and HBV in four of the included studies $[23,26,29,31]$.
The meta-analysis of gender among five included studies $[10,16,26,28,30]$ demonstrated that male and female participants were comparable in risk of Plasmodium spp. and HBV co-infection (p: 0.09) with a significant amount of heterogeneity across the included studies ( $\left.\mathrm{p}<0.0001, \mathrm{I}^{2}: 84 \%\right)$. This means that the pooled OR of gender in those five studies was not precisely estimated due to the high heterogeneity. In light of this result, the association between gender and risk of Plasmodium spp. and HBV co-infection should be further investigated, as the high proportion of males coinfected with Plasmodium spp. and HBV than females was reported in the study by Aernan et al. [30].

The differences in LFTs between Plasmodium spp. and HBV co-infection were performed using two studies $[14,28]$. The results demonstrated that no significance in any of the three LFTs, including AST, ALT, and total bilirubin levels, was found ( $p>0.05)$; there was a significant amount of heterogeneity among these studies $\left(\mathrm{p}<0.0001, \mathrm{I}^{2} \geq 99 \%\right)$. Considering individual studies in the meta-analysis, one study demonstrated lower ALT and AST levels in the Plasmodium spp. and HBV co-infection group than in the Plasmodium spp. monoinfection group [14], while another study demonstrated no difference in the ALT and AST levels between groups [28]. The included 2018 study by Kolawole and Kana indicated high ALT (54.5\%, 6/11 cases) and total bilirubin levels (72.7\%, 8/11 cases) among patients with Plasmodium spp. and HBV co-infection [33].

The present study had several limitations. First, there was a limited number of included studies reporting on the prevalence of, potential risk factors for, and LFTs among individuals with Plasmodium spp. and HBV co-infection and in comparison with Plasmodium spp. monoinfection. Therefore, the meta-analyses of the pooled prevalences, pooled ORs, and pooled MDs were limited by these data. Second, there was a significant amount of heterogeneity among the included studies, resulting in imprecise estimates of the pooled prevalence estimate of Plasmodium spp. and HBV coinfection. Therefore, the pooled prevalence estimates should be interpreted with caution. Third, the present study did not analyse the other potential risk factors for Plasmodium spp. and HBV co-infection since most of the included studies did not examine or report for these factors.

\section{Conclusion}

The present study demonstrated the status of Plasmodium spp. and HBV co-infection. The results of this study can be used to support health care communities, helping them to recognize the double burden of these two 
infections, control Plasmodium spp. parasites and provide regular $\mathrm{HBV}$ vaccinations.

\section{Supplementary information}

Supplementary information accompanies this paper at https://doi. org/10.1186/s12936-020-03428-w.

Additional file 1: Table S1. Age groups of Plasmodium spp. and HBV coinfection and monoinfection.

Additional file 2: Table S2. Laboratory parameters in Plasmodium spp. and HBV co-infection and monoinfection.

\section{Abbreviations}

ALT: Alanine aminotransferase; ANC: Antenatal care; AST: Aspartate aminotransferase; CCL2: C-C Motif Chemokine Ligand 2; Cl: Confidence interval; HBV: Hepatitis B virus; IFN: Interferon; LFTs: Liver function tests; NOS: Newcastle-Ottawa Scale; OR: Odds ratio; PCR: Polymerase chain reaction; PRISMA: Preferred Reporting Items for Systematic Reviews and Meta-analyses; RDT: Rapid diagnosis test; MD: Mean difference; Th1:Type 1 immune response; WHO: World Health Organization.

\section{Acknowledgements}

The authors would like to acknowledge Mr David C Chang, who edited the English language of this study.

\section{Authors' contributions}

MK and KUK participated in the study design, data analysis, and writing of the paper. Both authors read and approved the final manuscript.

\section{Funding}

This research was partially supported by the New Strategic Research (P2P) Project, Walailak University, Thailand. The funders had no role in the collection, analysis, and interpretation of the data.

\section{Availability of data and materials}

The datasets used during the current study are available without restriction.

Ethics approval and consent to participate

Not applicable.

\section{Consent for publication}

Not applicable.

\section{Competing interests}

The authors declare that there is no competing interests regarding the publication of this article.

Received: 13 May 2020 Accepted: 23 September 2020

Published online: 15 October 2020

\section{References}

1. Singh B, Kim Sung L, Matusop A, Radhakrishnan A, Shamsul SS, Cox-Singh $J$, et al. A large focus of naturally acquired Plasmodium knowlesi infections in human beings. Lancet. 2004;363:1017-24.

2. WHO. Guidelines for Malaria Vector Control [Internet]. Geneva: World Health Organization; 2019. https://www.who.int/malaria/publications/ atoz/9789241550499/en/. Accessed 29 Apr 2020.

3. WHO. Malaria [Internet]. Geneva: World Health Organization; 2018. https ://www.who.int/news-room/fact-sheets/detail/malaria. Accessed 29 Apr 2020

4. WHO. World malaria report 2019 [Internet]. Geneva: World Health Organization; 2019. https://www.who.int/malaria/publications/world-malar ia-report-2019/en/. Accessed 30 Apr 2020.

5. Liang TJ. Hepatitis B: the virus and disease. Hepatology. 2009;49(5 Suppl):S13-21.
6. Coppola N, De Pascalis S, Onorato L, Calo F, Sagnelli C, Sagnelli E. Hepatitis $B$ virus and hepatitis $C$ virus infection in healthcare workers. World J Hepatol. 2016:8:273-81.

7. WHO. Global hepatitis report 2017. https://www.who.int/hepatitis/publi cations/global-hepatitis-report2017-executive-summary/en/.

8. Freimanis GL, Owusu-Ofori S, Allain JP. Hepatitis B virus infection does not significantly influence Plasmodium parasite density in asymptomatic infections in Ghanaian transfusion recipients. PLoS ONE. 2012;7:e49967.

9. Andrade BB, Santos CJN, Camargo LM, Souza-Neto SM, Reis-Filho A, Clarêncio J, et al. Hepatitis B infection is associated with asymptomatic malaria in the Brazilian Amazon. PLoS ONE. 2011;6:e19841.

10. Aernan PT, Sar TT, Torkula SH. Prevalence of Plasmodia and hepatitis B virus co-infection in blood donors at Bishop Murray Medical Centre, Makurdi, Benue State Nigeria. Asian Pac J Trop Med. 2011;4:224-6.

11. Thursz MR, Kwiatkowski D, Torok ME, Allsopp CE, Greenwood BM, Whittle $\mathrm{HC}$, et al. Association of hepatitis B surface antigen carriage with severe malaria in Gambian children. Nat Med. 1995;1:374-5.

12. Brown AE, Mongkolsirichaikul $D$, Innis B, Snitbhan $R$, Webster HK. Falciparum malaria modulates viremia in chronic hepatitis $B$ virus infection. J Infect. 1992;166:1465-6.

13. Barcus MJ, Hien TT, White NJ, Laras K, Farrar J, Schwartz IK, et al. Short report: hepatitis $B$ infection and severe Plasmodium falciparum malaria in Vietnamese adults. Am J Trop Med Hyg. 2002;66:140-2.

14. Cruz LAB, Moraes MOA, Queiroga-Barros MR, Fukutani KF, Barral-Netto $M$, Andrade BB. Chronic hepatitis B virus infection drives changes in systemic immune activation profile in patients coinfected with Plasmodium vivax malaria. PLoSNegl Trop Dis. 2019;13:e0007535.

15. Afolabi O, Aremo A, Oluwabunmi H, Itansanmi I, Anuoluwa I. Malaria, hepatitis B and HIV /AIDS, and their co-infection among patients visiting health centres in Akure Nigeria. J Biomed Transl Res. 2018;2:22-6.

16. Dabo NT, Sharif AA, Muhammed Y, Sarkinfada F. Malaria and Hepatitis B co-infection in patients with febrile illnesses attending general outpatient unit of the MurtalaMuhammed Specialist Hospital, Kano, Northwest Nigeria. Bayero J Pure ApplSci. 2015;8:89-95.

17. Braga WS, Silva EB, Souza RA, Tosta CE. Seroprevalence of hepatitis $B$ and malaria infection in Labrea, Brazilian western Amazon: estimates of co-infection rates. Rev Soc Bras Med Trop. 2005;38:218-23.

18. Liberati A, Altman DG, Tetzlaff J, Mulrow C, Gotzsche PC, loannidis JP, et al. The PRISMA statement for reporting systematic reviews and meta-analyses of studies that evaluate health care interventions: explanation and elaboration. PLoS Med. 2009;6:e1000100.

19. Wells G, Shea B, O'Connell D, Peterson J, Welch V, Losos M, Tugwell P. The Newcastle-Ottawa Scale (NOS) for assessing the quality of nonrandomised studies in meta-analyses; 2013. https://www.ohri.ca/progr ams/clinical_epidemiology/oxford.asp.

20. Nyaga VN, Arbyn M, Aerts M. Metaprop: a Stata command to perform meta-analysis of binomial data. Arch Public Health. 2014;72:39.

21. Freeman MF, Tukey JW. Transformations related to the angular and the square root. Ann Math Statist. 1950;21:607-11.

22. WHO. Guidelines for the treatment of malaria. Geneva: World Health Organization; 2015. https://www.who.int/malaria/publications/ atoz/9789241549127/en/.

23. Anabire NG, Aryee PA, Abdul-Karim A, Abdulai IB, Quaye O, Awandare $G A$, et al. Prevalence of malaria and hepatitis $B$ among pregnant women in Northern Ghana: comparing RDTs with PCR. PLOS ONE. 2019;14:e0210365.

24. Gadia CLB, Manirakiza A, Tekpa G, Konamna X, Vickos U, Nakoune E. Identification of pathogens for differential diagnosis of fever with jaundice in the Central African Republic: a retrospective assessment, 2008-2010. BMC Infect Dis. 2017;17:735.

25. Helegbe GK, Aryee PA, Mohammed BS, Wemakor A, Kolbila D, Abubakari AW, et al. Seroprevalence of malaria and hepatitis b co-infection among pregnant women in tamale metropolis of Ghana: a crosssectional study. Can J Infect Dis Med Microbiol. 2018;2018:5610981.

26. Oyeyemi $O$, Amugo A. Plasmodium falciparum and hepatitis B virus infection in Nigerian urban population. Braz J Infect Dis. 2015;19:666-7.

27. Scotto G, Fazio V. Hepatitis B and asymptomatic malaria co-infection in Sub-Saharan African immigrants: epidemiological and clinical features of HBV infection. Rev Soc Bras Med Trop. 2018;51:578-83. 
28. Sharif AA, Getso MI, Yusuf MA, Yusuf I, Muhd IZ, Ahmad IM. Liver function biomakers in malaria and hepatitis B co-infection among patients with febrile illness. Int J Med Res Health Sci. 2016;5:29-322.

29. Abah AE, Onoja H, Amadi Fl. Prevalence of malaria and hepatitis B virus infections among pregnant women attending Federal Medical CenterOwerri. South Asian J Parasitol. 2019;3:1-5.

30. Abah AEUI. Co-infection of malaria and hepatitis B virus in Port Harcourt, Rivers State Nigeria. Int J Infect. 2019;6:e97033.

31. Adeleke MK, Adebimpe WO, Sam-Wobo SO, Wahab AA, Akinyosoye LS, Adelowo TO. Sero-prevalence of malaria, hepatitis $B$ and syphilis among pregnant women. Am J Microbiol. 2013;4:20-3.

32. Braga WS, Souza RA, Silva EB, Fonseca JC, Tosta CE. Co-infection between hepatitis B virus and malaria: clinical, serologic and immunologic aspects. Rev Soc Bras Med Trop. 2006;39:27-31 in Portuguese.

33. Kolawole OM, Kana SN. Hepatitis B virus and malaria co-infection causing significant changes in hematological and liver function indices in a cohort of subjects in Ilorin Nigeria. Int J Infect. 2018;5:e81528.

34. Omalu ICJ, Jibrin A, Olayemi IK, Hassan SC, Mgbemena C, Mgbemena A, Adeniran LA. Seroprevalence of malaria and hepatitis B ( $\mathrm{HBsAg})$ with associated risk factors among pregnant women attending antenatal clinic in General Hospital Minna, north-central Nigeria. Annu Rev Res Biol. 2012;2:83-8.

35. Wokem GN, Amacree MA. Malaria and hepatitis-B co-infection in relation to selected haematological parameters among attendees of two health facilities in Port Harcourt, Nigeria. Int J ApplSci Res Rev. 2018;5:54.
36. Yohanna JA, lorkyaa AA, Rotimi Jl, Nwibari BMW, Igavo PA, Dakul DA. Prevalence of malaria parasites and Hepatitis-B virus in patients attending two hospitals in Jos, Plateau State. Nigeria. Niger J Parasitol. 2016;37:87.

37. Brabin L, Brabin BJ, Dimitrakakis M, Gust I. Factors affecting the prevalence of infection with hepatitis B virus among non-pregnant women in the Alexishafen area of Papua New Guinea. Ann Trop Med Parasitol. 1989;83:365-74.

38. Schofield L, Grau GE. Immunological processes in malaria pathogenesis. Nat Rev Immunol. 2005;5:722-35.

39. Pasquetto V, Guidotti LG, Kakimi K, Tsuji M, Chisari FV. Host-virus interactions during malaria infection in hepatitis $B$ virus transgenic mice. J Exp Med. 2000;192:529-36.

40. Hosel M, Quasdorff M, Ringelhan M, Kashkar H, Debey-Pascher S, Sprinzl MF, et al. Hepatitis B v irus activates signal transducer and activator of transcription 3 supporting hepatocyte survival and virus replication. Cell MolGastroenterolHepatol. 2017;4:339-63.

41. Hojo-Souza NS, Pereira DB, de Souza FS, de Oliveira Mendes TA, Cardoso MS, Tada MS, et al. On the cytokine/chemokine network during Plasmodium vivax malaria: new insights to understand the disease. Malar J. 2017;16:42.

\section{Publisher's Note}

Springer Nature remains neutral with regard to jurisdictional claims in published maps and institutional affiliations.
Ready to submit your research? Choose BMC and benefit from:

- fast, convenient online submission

- thorough peer review by experienced researchers in your field

- rapid publication on acceptance

- support for research data, including large and complex data types

- gold Open Access which fosters wider collaboration and increased citations

- maximum visibility for your research: over $100 \mathrm{M}$ website views per year

At BMC, research is always in progress.

Learn more biomedcentral.com/submissions 